\title{
The Larvae of Chironomidae of the Holarctic Region - Keys and diagnoses
}

\author{
Oliver Heiri \\ Aquatic Palaeoecology, Institute of Plant Sciences and Oeschger Centre for Climate Change Research \\ Altenbergrain 21, CH-3013 Bern, Switzerland. \\ E-mail: oliver.heiri@ips.unibe.ch
}

The Wiederholm 1983 key to the larvae of the Holarctic Chironomidae was by far the most used book during my $\mathrm{PhD}$ and my post-doctoral years. It shaped my understanding of chironomid classification and identification, and provided the basis for most of my work as a chironomid ecologist and palaeoecologist. It is, therefore, with high expectations (will there be new taxa?) and some dread (will I have to rethink my classification?) that I opened the copy of the revised "Chironomidae of the Holarctic region. Key and diagnoses - Larvae" that was kindly provided to me by Lennart Cederholm at Scandinavian Entomology Ltd. At first glance, the book, edited by Trond Andersen, Pete Cranston, and John Epler, does not look much different than the original edited by Torgny Wiederholm. It has the same cover, color, and is similarly massive, although the format has changed - the book has now become several centimeters broader. My first impression was one of slight disappointment.

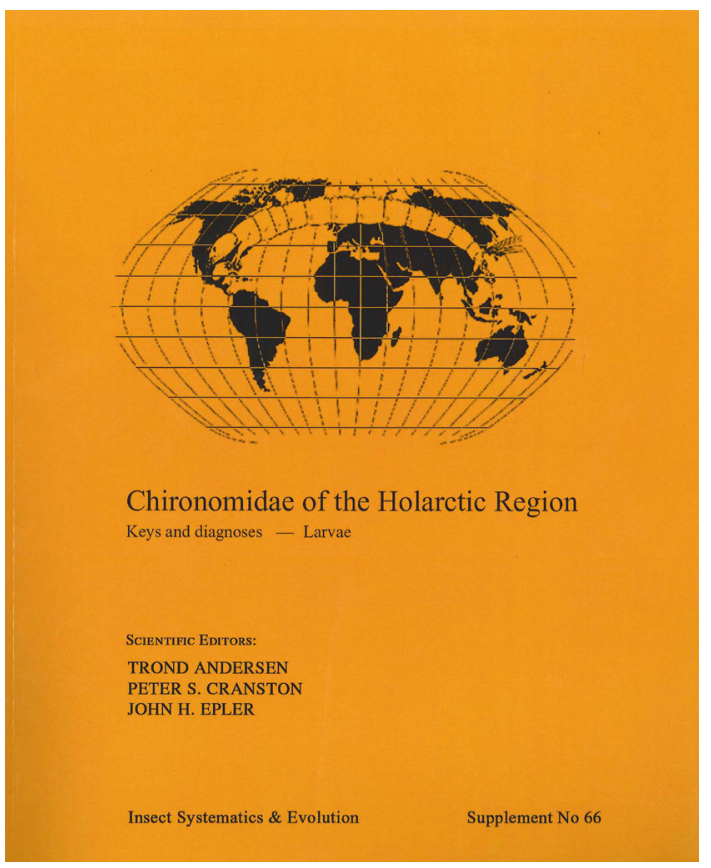
Many of the figures are obviously identical as in

the 1983 version, but not as well reproduced. In many sections the text also remains more or less the same, especially in the larval descriptions for the different genera. The chapters are presented in a similar order, starting with an introduction and a section describing the morphology of the larvae, followed by a key to the different subfamilies. These initial chapters are followed by sections dealing with the different subfamilies: Buchonomyiinae, Podonominae, Tanypodinae, Telmatogetoninae, Diamesinae, Prodiamesinae, Orthocladiinae, and Chironominae. The book also includes a foreword and an index of the discussed Holarctic chironomid taxa.

However, a closer look at the different sections reveals a number of significant changes. All of the chapters have been updated. For example, the introduction now includes a short part on identification based on genetic analyses. The second chapter, originally consisting of a key to the subfamilies only, now includes a detailed description of the morphology of chironomid larvae. However, the most relevant improvement is that the sections on the different subfamilies now contain a larger number of generic descriptions and illustrations. For example, the chapter on Orthocladiinae now includes descriptions of Aagaardia, Allocladius, Apometriocnemus, Chasmatonotus, Compterosmittia, Eretmoptera, Neobrillia, Phytotelmatocladius, Platysmittia, Semiocladius, Stictocladius, Tavastia, Tempisquitoneura, Trichochilus, Unniella, and Vivacricotopus, all genera without larval diagnosis in the 1983 version of the key. The chapter on Tanypodinae has been revised and now includes 42 generic diagnoses, compared with 36 in the original version of the book. Several nomenclatural actions are proposed for the Tanypodinae and two figures are included which provide detailed illustrations of the cephalic setation for 18 genera of this subfamily. The order the genera are discussed in the text has also been modified. The authors now first describe the non-Pentaneurini genera, followed by the Pentaneurini and a special section on the Thienemannimyia-group. This revised structure will certainly help beginners to separate the main larval groups within the Tanypodinae and to realize that different larval structures will have to be examined to identify them. The structure of the section on Chironominae has also been revised. The chapter now first deals with the larvae of the Chironomini (including Pseudochironomus and Manoa), followed by the Tanytarsini. Again, it can be expected that this structure will facilitate the identification of Chironominae larvae for all those not yet familiar with the 
different genera within this subfamily. Several new genera are discussed (e.g. Kribiodorum, Xestochirono$m u s$ ). Also, the sections for some genera have been expanded significantly. For example, the description of Polypedilum now includes a description of eight different subgenera within the genus and the description of Micropsectra includes notes on the phylogeny of this taxon. Similar changes and improvements are apparent in the other chapters that were already available in the 1983 version of the key (e.g. Prodiamesinae, Diamesinae), although the modifications in some of them (e.g. Telmatogetoninae, Podonominae) are really very minor.

At first glance not that dissimilar to the 1983 "Chironomidae of the Holarctic Region" larval key, the new book edited by Andersen and coworkers must nevertheless be considered a milestone for chironomid research. Thirty years after the publication of the original it again includes up-to-date diagnoses for the larvae of Holarctic chironomid genera in a single book, and provides detailed keys that will allow the identification of most fourth instar larvae, but also of many younger stages and fossil head capsules. The experienced chironomidologist will profit from the added information and the clear overview over Holarctic chironomid larvae compiled in the book. However, most of us have assembled our own little library of chironomid keys and publications and will know exactly which one to consult when dealing with certain chironomid subfamilies, genera or species collected from different parts of the Northern Hemisphere. It will be the novices and less experienced chironomid systematists, ecologists and palaeoecologists in training that will most significantly benefit from the new book. They will find an introduction to the collection, preparation and identification of all chironomid genera presently known for the Holarctic in a single reference manual, together with detailed descriptions and ecological notes on the discussed taxa. Since the book now includes more taxa from the southern Nearctic and eastern Palaearctic it is also more widely applicable than the 1983 version of the key.

The original "Chironomidae of the Holarctic Region" larval key edited by Wiederholm provided the basis for three decades of progress in the field of chironomid systematics and ecology, and allowed the expansion and growth of new subfields such as chironomid palaeoecology. The revised key edited by Andersen, Cranston and Epler will hopefully provide a similar stimulus for the field. The typesetting and printing of the revised book is of lower quality than the original, and I found a relatively large number of typographical and printing errors. However, the editors at Insect Systematics \& Evolution have informed me that the book has now been corrected and reprinted, so hopefully many of these errors will have been removed. It is difficult to imagine the amount of work that must have gone into producing this revision - hopefully the authors and editors will be compensated by the satisfaction of seeing it widely used by students and experienced colleagues alike. I will certainly recommend the book to my own students and to colleagues working with fossil chironomid larvae, especially since it is available at what must be considered a very reasonable price for such an extensive compilation. I have already started using it in my own research, and have sent my own, old copy of the original 1983 version of the guide to its well-deserved retirement on the top shelf of my bookcase.

For information on how to purchase a copy of the book, please see announcements on page 46. 